\title{
The Influence of the Parathyroid Glands on the Hypercalcemia of Experimental Magnesium Depletion in the Rat
}

\author{
H. J. Gitelman, S. Kukolj, and L. G. Welt \\ From the Department of Medicine, University of North Carolina School \\ of Medicine, Chapel Hill, North Carolina
}

A в S T R A C T Magnesium-deficient rats develop significant hypercalcemia, hypophosphatemia, and hyperphosphaturia. These changes suggest a state of hyperparathyroidism. This study examines the regulation of parathyroid gland activity in magnesium-deficient rats. Magnesium deficiency was induced in intact and chronically parathyroidectomized animals by feeding them a diet free of this cation. Control animals were pair fed and treated identically except for the inclusion of magnesium in their gavage solution.

Magnesium-deficient rats with intact parathyroid glands developed significant hypercalcemia and hypophosphatemia. In addition, the concentration of ionic calcium in plasma was significantly elevated. In contrast, magnesium-deficient parathyroidectomized animals did not have a higher level of calcium in plasma than their nondeficient controls; they developed a decreased concentration of ionic calcium in the alssence of a difference in the concentration of phosphate in plasma when compared with appropriate controls. The increased urinary excretion of phosphate was independent of the parathyriod status of the animals.

It can be concluded that the hypercalcemia and hypophosphatemia of magnesium deficiency demands parathyroid gland activity and that the

Dr. Kukolj's current address is Torre Molinos 601, Las Condes, Santiago, Chile. Address requests for reprints to Dr. Louis G. Welt, Iepartment of Medicine, University of North Carolina School of Medicine, Chapel Hill, N. C. 27514.

Received for publication 22 August 1966 and in revised form 25 September 1967. regulation of this activity is modified in the magnesium-deficient state to permit the maintenance of an elevated concentration of ionic calcium in plasma. Additional explanations must be found for the hyperphosphaturia.

\section{INTRODUCTION}

Rats rendered deficient by feeding them a diet free of magnesium develop, in addition to hypomagnesemia, significant hypercalcemia, hypophosphatemia, and hyperphosphaturia (1-3). These changes suggest a state of hyperparathyroidism. In addition, there are several observations which suggest an interrelationship between magnesium homeostasis and parathyroid activity (4-10). This study examines the role of the parathyroid gland in magnesium-deficient rats in terms of $(a)$ the chemical changes alluded to and $(b)$ the regulation of ionic calcium in plasma. The results are consistent with the hypothesis that the parathyroid regulatory mechanisms involved in calcium homeostatis are altered in the magnesium-deficient state.

\section{METHODS}

Intact and parathyroidectomized Sprague-Dawley rats of approximately $225 \mathrm{~g}$ weight were housed in individual metabolic cages and subdivided into two subgroups each. All the animals were pair fed with approximately $10 \mathrm{~g}$ of a diet which was adequate in all nutritional aspects except that it contained only trivial quantities of sodium, potassium, chloride, phosphorus, and magnesium (Table I). The animals were gavaged daily with $5 \mathrm{ml}$ of a solution of composition described in Table II. The experimental (magnesium-deficient) groups received a gavage 
solution prepared without magnesium. Control animals were treated identically except for the inclusion of magnesium in their gavage solution. Demineralized water was allowed ad lib. The rats in the parathyroidectomized group had been parathyroidectomized by cautery 1 month before this study. The adequacy of parathyroidectomy was ascertained by the demonstration of a calcium concentration in plasma of fasting rats of $3 \mathrm{mEq} /$ liter (i.e. $6 \mathrm{mg} / 100 \mathrm{ml}$ ) or less $3-4 \mathrm{wk}$ after the operative procedure. Animals with higher concentrations of calcium in plasma were discarded so that those used could be properly assumed to have had total or near total parathyroidectomy.

The period of study was 4 or 6 wk. During the last 5 days of the 4 wk experimental period, the rats were placed in metabolic cages designed for the collection of urine in mineral oil with the avoidance of fecal contamination. At the end of the experimental period, food was withdrawn from the animals. $12 \mathrm{hr}$ later, the animals were anesthetized with sodium pentobarbital $(5 \mathrm{mg} / 100 \mathrm{~g}$ of body weight) administered intraperitoneally and then exsanguinated from the abdominal aorta. We used $10 \mathrm{U}$ of heparin per $\mathrm{ml}$ of whole blood as anticoagulant after demonstrating that it did not interfere with any subsequent chemical analysis. In some animals a separate aliquot was collected with potassium EDTA in order to minimize the hydrolysis of phosphate esters and hence obtain an accurate measurement of inorganic phosphate.

In some experiments, fat-free dry solids were prepared from whole carcass by conventional technics $(11,12)$ and were $(a)$ digested with $0.75 \mathrm{~N}$ nitric acid for estimation of the sodium, potassium, and chloride; $(b)$ ashed at $550^{\circ} \mathrm{C}$ in platinum crucibles for $12-18 \mathrm{hr}$, then dissolved in $0.24 \mathrm{~N}$ hydrochloric acid for determination of calcium and magnesium; and $(c)$ ashed, as in $(b)$, for the estimation of phosphorous after evaporating $2 \mathrm{ml}$ of $0.25 \mathrm{M}$ magnesium acetate solution with $100 \mathrm{mg}$ of fat-free dry solids to prevent the loss of phosphorous during the ashing procedure.

Parathormone administration. To evaluate the effect of increased amounts of parathormone on the partition of calcium in plasma, we administered commercial parathyroid extract ${ }^{1}$ ( $35 \mathrm{U} / 100 \mathrm{~g}$ of body weight per $24 \mathrm{hr}$ ) subcutaneously at 8 -hr intervals to intact rats on a normal diet. Control animals received identical doses of normal

${ }^{1} \mathrm{We}$ are indebted to Dr. Glenn W. Irwin of the Eli Lilly Company for the parathyroid extract.

TABLE I

Electrolyte Content of the Basal Diet

\begin{tabular}{lc}
\hline & mmoles $/ 100$ g diet \\
$\mathrm{Na}$ & 0.37 \\
$\mathrm{~K}$ & 0.05 \\
$\mathrm{Cl}$ & 1.66 \\
$\mathrm{Ca}$ & 7.91 \\
$\mathrm{P}$ & 4.73 \\
$\mathrm{Mg}$ & 0.25 \\
\hline
\end{tabular}

TABLE II

Normal gavage, each $5 \mathrm{ml}$ contains:

\begin{tabular}{|c|c|}
\hline & mmoles \\
\hline $\mathrm{Na}$ & 1.25 \\
\hline K & 2.00 \\
\hline $\mathrm{Cl}$ & 2.50 \\
\hline $\mathrm{Mg}$ & 0.70 \\
\hline \multirow[t]{2}{*}{$\mathbf{P}$} & 0.75 \\
\hline & g/liler \\
\hline $\mathrm{NaCl}$ & 5.845 \\
\hline $\mathrm{NaH}_{2} \mathrm{PO}_{4} \cdot \mathrm{H}_{2} \mathrm{O}$ & 20.6997 \\
\hline $\mathrm{KCl}$ & 29.8200 \\
\hline $\mathrm{MgSO}_{4} \cdot 7 \mathrm{H}_{2} \mathrm{O}$ & 34.51 \\
\hline
\end{tabular}

$\mathrm{No} \mathrm{Mg}$ gavage, prepare as above without $\mathrm{MgSO}_{4}$

saline. After 3 days of this regimen the animals were sacrificed as previously described and their plasma was examined.

The chemical methods were as follows: urea nitrogen with the autoanalyzer utilizing the colorimetric reaction of diacetyl monoxime (13); sodium and potassium with conventional internal standard flame photometer; chloride with Cotlove (Buchler Instruments Inc., Fort Lee, N. J.) chloridometer (14); calcium by a modification of an automated method which eliminates the interference of magnesium by the addition of 8-hydroxyquinoline (15) ; magnesium by an automated spectrophotometric method (16); phosphate by an automated modification of a molybdenum blue method (17); plasna proteins by biuret reaction (18); citrate by a pentabromacetone technique (19).

Protein-free plasma ultrafiltrates were prepared by high speed centrifugation through LSG-60 membrance filters of $5 \mu$ pore size. The ultrafiltration was performed in nylon filtering capsules designed by the Schleicher \& Schuell Co. (Keene, N. H.), for use with the Sorvall (Ivan Sorvall, Inc., Norwalk, Conn.) (Fig. 1). This rotor permits eight individual specimens to be centrifuged simultaneously under a constant atmosphere. The ultrafiltration procedure is performed in the following manner. The membrane filters, suspended in distilled water for at least $24 \mathrm{hr}$ before use, are blotted dry for assembly in the filter support. A $2.5 \mathrm{ml}$ plasma sample from an individual rat is placed into the upper portion of each capsule and gassed with a humid 5\% CO nitrogen mixture. The lower portion of the filtration capsule is flushed with this gas mixture before final assembly of the capsule which is then inserted into the rotor head. After thorough equilibration with the $\mathrm{CO}_{2}$ mixture, the rotor head is sealed and the plasma samples are centrifuged at $37^{\circ} \mathrm{C}$ and $15,000 \mathrm{rpm}$ for $50 \mathrm{~min}$. At the end of this period, approximately $1.5 \mathrm{ml}$ of proteinfree ultrafiltrate is removed from the lower portion of the capsule for further analysis. In all experiments, control and experimental plasma samples were run simultaneously to randomize any variation in the centrifuga tion technique. 


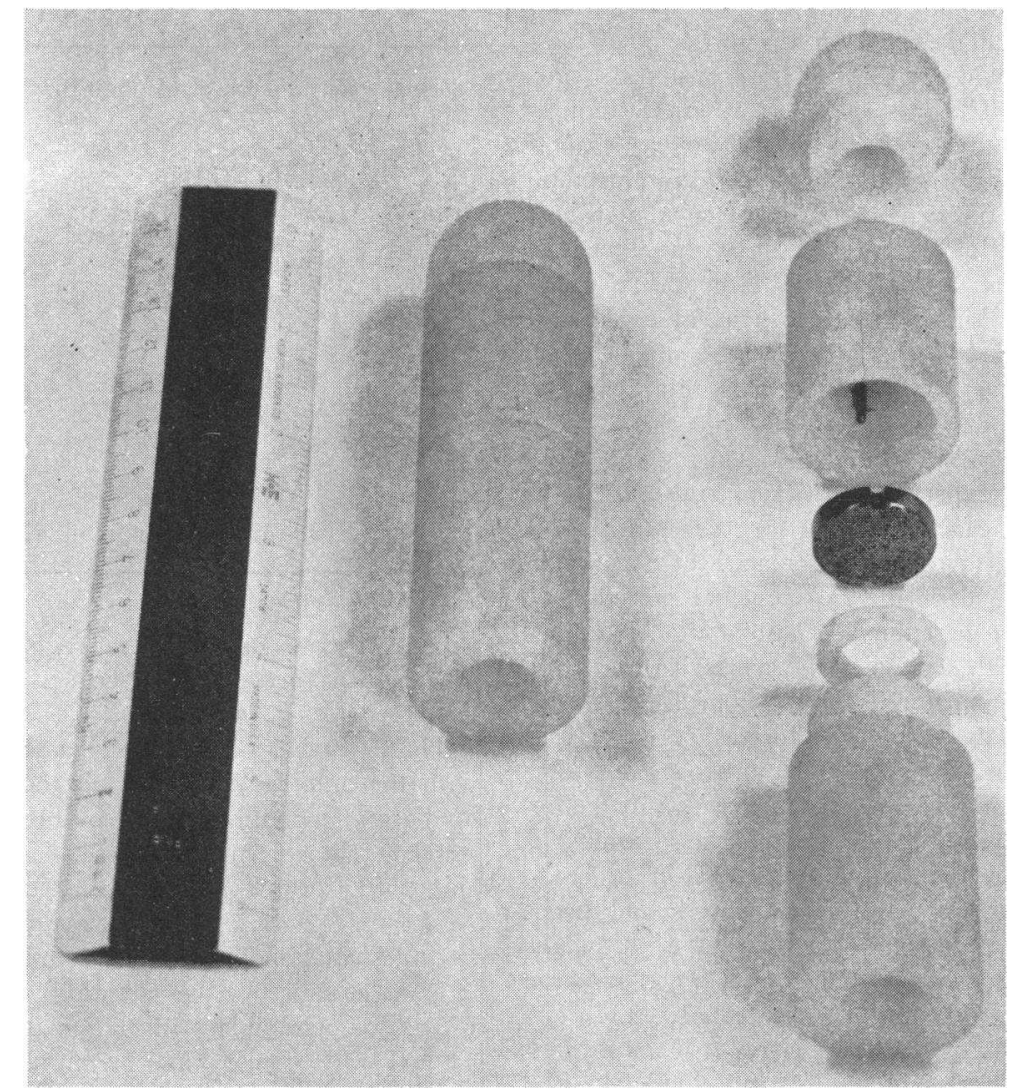

FIGURE 1 Nylon ultrafiltration capsule for use in the Sorvall SS-34 rotor. Not illustrated are the membrane filter and a thin stainless steel washer which are inserted between the sintered stainless steel filter support and the teflon $\mathrm{O}$ ring.

To evaluate whether the degree of ultrafiltration empluyed in these studies altered the observed total or ionic calcium content of the ultrafiltrate, we centrifuged plasma samples for periods ranging from 20 to $55 \mathrm{~min}$. No systematic alteration in the calcium composition of the ultrafiltrate was observed. Moreover, the concentration of calcium in an ultrafiltrate prepared from plasma was not altered when plasma was diluted by $30 \%$ with a solution containing concentrations of calcium identical with those observed in the ultrafiltrates of undiluted plasma samples. Accordingly, the Donnan equilibrium was assumed to be constant with this technique and the values obtained were not corrected for this factor.

The adequacy of the ultrafiltration procedure was further verified by preparation of ultrafiltrates from plasma samples of normal human volunteers. In 12 subjects a percentage ultrafiltration of $50.7 \%$ was obtained for calcium, which is in agreement with published values found with alternative procedures (20).

The spectrophotometric method of Walser (21) was modified to permit an automated determination of ionic calcium. The manifold is diagrammed in Fig. 2. In this procedure a $0.06 \mathrm{M}$ sodium cyanide and $0.10 \mathrm{M}$ sodium chloride solution containing $0.3 \%$ Brij-35 [polyoxyethylene (23) lauryl ether, Atlas Chemical Industries Inc., Wilmington, Del.] is initially added to the ultrafiltrate to remove heavy metal interference and then mixed with a solution containing a $0.15 \mathrm{M}$ Tris (hydroxymethyl) aminomethane solution and sufficient hydrochloric acid (approximately $0.16 \mathrm{~mole} / \mathrm{liter}$ ) to achicve a physiologic $\mathrm{pH}$ and ionic strength in the blank circuit. In these experiments, the buffer was adjusted to yield a final $\mathrm{pH}$ of 7.45 , since this was the experimentally determined $\mathrm{pH}$ of magnesium-deficient and control rat plasmas equilibrated with the $5 \% \mathrm{CO}_{2}$ gas mixture. $\Lambda$ fter measurement of the blank absorbance, a $15 \mathrm{mg} / 100 \mathrm{ml}$ murexide solution in $0.15 \mathrm{M}$ Tris (hydroxymethyl) aminomethane buffer $\mathrm{pH}$ 7.45 , ionic strength $0.16 \mu$ is added and the resultant absorbancy is measured at $480 \mu$. Since the blank optical density is diluted by the further addition of the murexide reagent, the blank absorbancy is multipled by 0.9 before its subtraction from the optical density of the calciummurexide solution. The ionic calcium value of the sample is derived from the corrected optical density. Appropriate amounts of calcium in $0.16 \mathrm{~m}$ sodium chloride were used to standardized the procedure. To enhance the stability of 


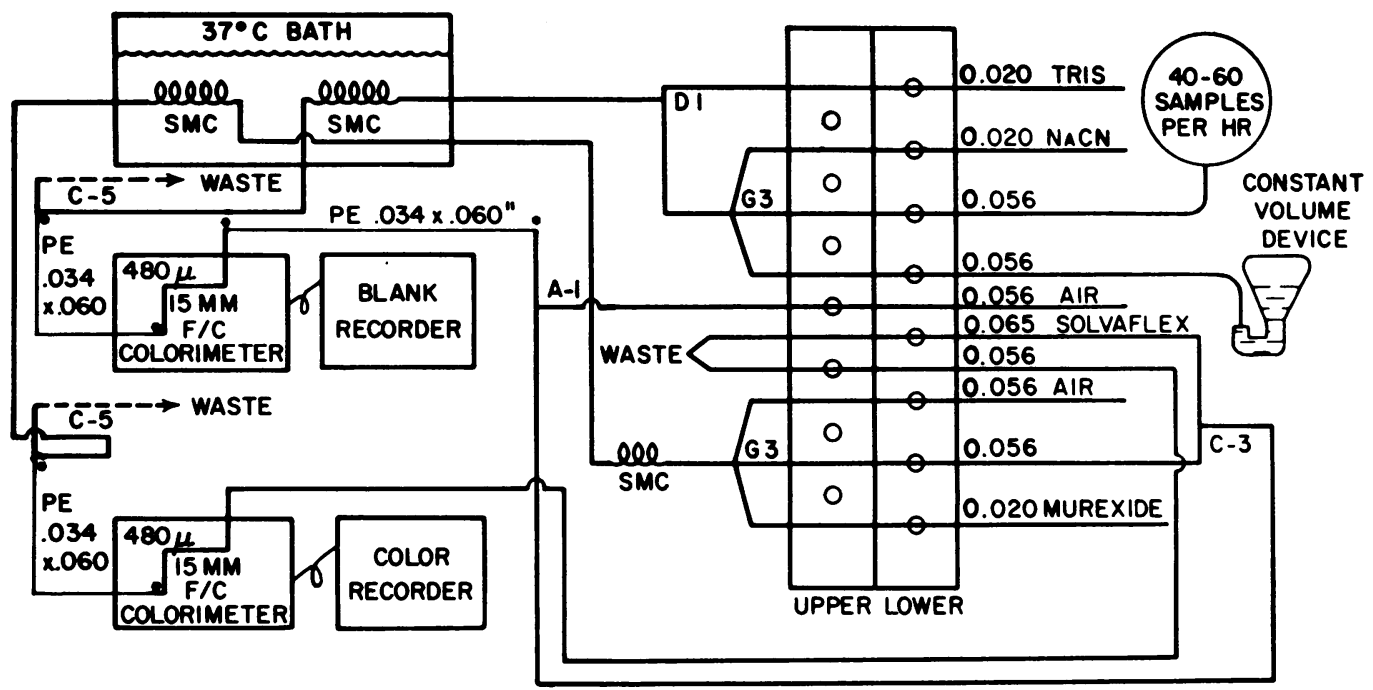

Figurf 2 Flow diagram for the determination of ionic calcium in plasma ultrafiltrates. Standard tygurn tubing is used except as noted. The constant volume device contains $0.16 \mathrm{M} \mathrm{NaCl}$; otherwise the reagent composition is specified in the text. Extra springs may be needed below the pump platen to provide adequate pressure on the pump tubes. SMC, single mixing coil; PE, polyethylene.

the murexide-buffer solution, we extracted the buffer with $0.1 \%$ dithizone in chloroform, and removed the excess dithizone by two additional chloroform extractions. The murexide solution was prepared shortly before use utilizing gentle inversion to dissolve the murexide reagent. After settling, the clear supernatant was decanted into a polyethylene container to free the solution of undissolved material which adversely affects the stability of the solution. The complexed fraction of calcium was calculated by subtracting the ionic calcium value from the total ultrafilterable calcium. In all instances, the measured total ultrafilterable calcium was greater than the measured ionic calcium concentration.

The accuracy of this technique was verified in the following manner: $(a)$ the $\mathrm{pK}$ dissociation for calcium citrate measured in solutions of $0.16 \mathrm{M} \mathrm{NaCl}$ containing 2 and $4 \mathrm{mEq}$ of calcium per liter and citrate concentrations ranging from 0.25 to $2.0 \mathrm{~mm}$ was $3.11 \pm 0.06$, which agrees with published dissociation constants for this complex under physiologic conditions (22); (b) there was the absence of significant interference with magnesium, copper, iron, and zinc; and $(c)$ ionic calcium

TABLE III

Plasma Values after $4 \mathrm{Wk}$ of the Experimental Regimen

\begin{tabular}{|c|c|c|c|c|}
\hline & \multicolumn{2}{|c|}{ Intact rats } & \multicolumn{2}{|c|}{ Parathyroidectomized rats } \\
\hline & Control (12) & $\begin{array}{c}\text { Magnesium } \\
\text { deficient (10) }\end{array}$ & Control (6) & $\begin{array}{c}\text { Magnesium } \\
\text { deficient (11) }\end{array}$ \\
\hline $\mathrm{Mg}, m E q /$ liter & $1.78 \pm 0.05$ & $0.76 \pm 0.05^{*}$ & $1.90 \pm 0.07$ & $0.94 \pm 0.07^{*}$ \\
\hline $\mathrm{Ca}, m E q /$ liter & $5.11 \pm 0.03$ & $5.32 \pm 0.03 \ddagger$ & $2.59 \pm 0.16$ & $2.76 \pm 0.12$ \\
\hline $\mathrm{P}, \mathrm{mg} / 100 \mathrm{ml}$ & $6.21 \pm 0.18$ & $5.12 \pm 0.28 \ddagger$ & $10.41 \pm 0.66$ & $10.59 \pm 0.71$ \\
\hline Urea $\mathrm{N}, \mathrm{mg} / 100 \mathrm{ml}$ & $19.0 \pm 1.0$ & $23.0 \pm 1.3 \S$ & $22.0 \pm 1.3$ & $33.0 \pm 3.03 \|$ \\
\hline Na, $m E q / l i t e r$ & $145.0 \pm 0.9$ & $145.0 \pm 0.7$ & $142.0 \pm 0.5$ & $144.0 \pm 0.9$ \\
\hline $\mathrm{K}, m E q /$ liter & $4.06 \pm 0.06$ & $4.16 \pm 0.12$ & $4.06 \pm 0.09$ & $4.00 \pm 0.10$ \\
\hline $\mathrm{Cl}, m E_{q} /$ liter & $109.0 \pm 0.09$ & $107.0 \pm 0.6$ & $96.5 \pm 0.8$ & $101.0 \pm 1.2$ \\
\hline Total protein, $\mathrm{g} / 100 \mathrm{ml}$ & $6.0 \pm 01.0$ & $5.7 \pm 0.12$ & $5.9 \pm 0.15$ & $6.0 \pm 0.22$ \\
\hline
\end{tabular}

All values given as mean \pm SEM. Numbers in parentheses indicate the number of animals.

* Significantly different from controls as $P<0.001$.

$\ddagger$ Significantly different from controls as $P<0.01$.

\$ Significantly different from controls as $P<0.02$.

\| Significantly different from controls as $P<0.05$. 
TABLE IV

Plasma Values after 6 Wk of the Experimental Regimen

\begin{tabular}{|c|c|c|c|c|}
\hline & \multicolumn{2}{|c|}{ Intact rats } & \multicolumn{2}{|c|}{ Parathyroidectomized rats } \\
\hline & Control (8) & $\begin{array}{c}\text { Magnesium } \\
\text { deficient (15) }\end{array}$ & Control (12) & $\begin{array}{c}\text { Magnesium } \\
\text { deficient (12) }\end{array}$ \\
\hline \multicolumn{5}{|l|}{$\mathrm{Mg}^{++}, m E q /$ liter } \\
\hline Total & $1.73 \pm 0.04$ & $0.36 \pm 0.02^{*}$ & $1.46 \pm 0.04$ & $0.41 \pm 0.04^{*}$ \\
\hline \multicolumn{5}{|l|}{$\mathrm{Ca}^{++}, m E q /$ liter } \\
\hline Total & $5.08 \pm 0.05$ & $5.52 \pm 0.04^{*}$ & $3.04 \pm 0.08$ & $2.44 \pm 0.08^{*}$ \\
\hline Protein bound & $2.08 \pm 0.04$ & $2.08 \pm 0.03$ & $1.49 \pm 0.04$ & $1.14 \pm 0.04^{*}$ \\
\hline Ultrafilterable & $3.00 \pm 0.01$ & $3.44 \pm 0.03^{*}$ & $1.55 \pm 0.05$ & $1.30 \pm 0.06^{*}$ \\
\hline Ionic & $2.87 \pm 0.03$ & $3.12 \pm 0.02^{*}$ & $1.29 \pm 0.04$ & $1.01 \pm 0.05^{*}$ \\
\hline Complexed & $0.13 \pm 0.02$ & $0.31 \pm 0.03^{*}$ & $0.27 \pm 0.01$ & $0.29 \pm 0.03$ \\
\hline BUN, $m g / 100 m l$ & $16.0 \pm 1.0$ & $25.0 \pm 1.5^{*}$ & $22.0 \pm 1.6$ & $30.0 \pm 3.4$ \\
\hline Total protein, $\mathrm{g} / 100 \mathrm{ml}$ & $6.4 \pm 0.1$ & $5.5 \pm 0.1^{*}$ & $7.2 \pm 0.1$ & $6.6 \pm 0.1 \ddagger$ \\
\hline Citrate, mmoles/liter & $0.21(7) \pm 0.004$ & $0.32(12) \pm 0.012^{*}$ & $0.30(8) \pm 0.021$ & $0.33(7) \pm 0.015$ \\
\hline
\end{tabular}

All values gives as mean \pm SEM. Numbers in parentheses indicate the number of animals.

* Significantly different from controls at $P<0.001$.

$\ddagger$ Significantly different from controls at $P<0.01$.

concentrations in plasma ultrafiltrates prepared from 12 normal subjects were $2.42 \pm 0.093 \mathrm{mEq} /$ liter which is compatible with other reported measurements (20). Since a variable decrease was observed in the values of all fractions of the calcium partition after storage of plasma or plasma ultrafiltrate, the entire analysis of the calcium partition was completed on the same day the samples were obtained.

\section{RESULTS}

The usual changes were noted in the magnesiumdeficient rats, i.e., peripheral vasodilatation and neuromuscular irritability including convulsive movements $(1,2)$. There was a difference between intact and parathyroidectomized rats in that the latter showed these changes in a delayed and attenuated way. The rats with intact parathyroid glands gained approximately $10 \%$ of their initial weight whereas the magnesium-depleted parathyroidectomized rats lost about $8 \%$ of their initial weight. The results of the plasma chemical analyses at the end of $4 \mathrm{wk}$ of the experimental regimen are presented in Table III. The concentrations of sodium, potassium, chloride, and total protein are the same in all groups whereas there are significant differences in the values of magnesium, calcium, phosphate, and urea nitrogen. The concentration of magnesium in plasma in both control groups is similar and both magnesium-deficient groups dem- onstrate a striking hypomagnesemia of similar magnitude.

As for the calcium and phosphorus values, only the magnesium-deficient rats with intact parathyroid glands have a significant hypercalcemia and hypophosphatemia. The parathyroidectomized rats demonstrate the expected low calcium and high phosphorus levels of the parathyroidectomized state. However, in contrast to the animals with in-

TABLE V

Effect of Parathyroid Extract on the Partition of Plasma Ca

\begin{tabular}{lcc}
\hline & $\begin{array}{c}\text { Control } \\
\text { rats }(7)\end{array}$ & $\begin{array}{c}\text { Parathyroid } \\
\text { extract-treated } \\
\text { rats }(7)\end{array}$ \\
\hline & & $\begin{array}{c}(35 U / 100 \mathrm{~g} \\
\text { per day) }\end{array}$ \\
& & $\times 3$ days \\
$\mathrm{Ca}^{++}, m E q /$ liter & & $5.82 \pm 0.11^{*}$ \\
Total & $5.10 \pm 0.03$ & $2.36 \pm 0.08 \ddagger$ \\
Protein bound & $2.14 \pm 0.04$ & $3.46 \pm 0.04^{*}$ \\
Ultrafilterable & $2.96 \pm 0.02$ & $3.13 \pm 0.04^{*}$ \\
Ionic & $2.78 \pm 0.03$ & $0.33 \pm 0.07$ \\
Complexed & $0.18 \pm 0.01$ & $1.58 \pm 0.06$ \\
Mg ${ }^{++} m E q / l i l e r$ & $1.69 \pm 0.04$ & $5.7 \pm 0.1$ \\
Total protein, $g / 100 m l$ & $5.9 \pm 0.1$ & \\
\hline
\end{tabular}

All values given as mean \pm SEM. Numbers in parentheses indicate the number of animals.

* Significantly different from controls at $P<0.001$.

$\ddagger$ Significantly different from controls at $P<0.01$. 
tact parathyroid glands, the magnesium-deficient parathyroidectomized animals do not have a significantly higher level of calcium or a dininished level of phosphorus when compared with their appropriate controls.

The results of the plasma chemical analyses of magnesium-deficient animals at the end of $6 \mathrm{wk}$ of the experimental regimen are tabulated in Table IV. The chemical alterations observed in the magnesium-deficient animals with intact parathyroid glands are similar to those demonstrated after 4 wk of the experimental regimen. The most significant feature of these observations is the increase in the concentration of ionic calcium. This increment plus the higher concentration of complexed calcium accounts for the increased concentration of total calcium noted in the magnesium-deficient group. The concentration of protein-bound calcium in the experimental and control groups is identical. This is presumably a consequence of the sinultaneous elevation in the concentration of ionic calcium and the diminution of total protein levels in the magnesium-deficient group, since the calculated value for the dissociation of calcium proteinate is not significantly altered in the experimental group. In contrast to these observations in the intact animals, parathyroidectomized rats developed significant hypocalcemia when compared to their nonmagnesium-deficient parathyroidectomized controls after $6 \mathrm{wk}$ of the experimental regimen. The most significant feature of these observations is the diminution in the ionic calcium fraction of the calcium partition. In these animals the decrease in protein-bound and ionic calcium fractions accounts for the significant diminution in the concentration of total calcium in plasma. The concentration of citrate in plasma is of interest in both groups since alterations in this parameter were associated with changes in the concentration of complexed calcium. This association constitutes an additional validation of the technique utilized to partition the plasma calcium.

The response of intact rats on a normal diet to the administration of commercial parathyroid extract is tabulated in Table $\mathrm{V}$. The experimental animals developed significant hypercalcemia which is manifest in the major fractions of the plasma calcium. In this instance, the protein-bound calcium value demonstrates a slight but nevertheless significant elevation in the parathyroid extracttreated group which would be anticipated from a rise in ionic calcium without alteration to total protein level. The calculated dissociation constants for calcium proteinate were not significantly different. It is of interest that the concentration of magnesium in plasma was not significantly altered by the administration of parathyroid extract.

In Table VI, the urinary findings at the end of $4 \mathrm{wk}$ of the experimental regimen are presented as pooled 5-day values. Both intact and parathyroidectomized magnesium-deficient groups present a similar pattern of urinary excretion : a very striking increase in the excretion of phosphate, a very low excretion of magnesium, and a normal excretion of calcium.

The composition of total carcass is presented in Table VII with results expressed as mmoles/100 $\mathrm{g}$ of fat-free dry solids. Both intact and parathyroidectomized magnesium-deficient groups present a significant and similar decrease in the magnesium content of about $20 \%$. Calcium content is significantly increased only in the magnesium-cleficient rats with intact parathyroid glands. Both the intact and parathyroidectomized magnesium-deficient rats show an increased content of phosphorus. Sodium is increased independently of the parathyroid status

TABLE VI

Urinary Excretion after $4 \mathrm{Wk}$ of the Experimental Regimen

\begin{tabular}{lccccc}
\hline & \multicolumn{2}{c}{ Intact rats } & & \multicolumn{2}{c}{ Parathyroidectomized rats } \\
\cline { 2 - 3 } \cline { 5 - 6 } & Control (12) & $\begin{array}{c}\text { Magnesium (10) } \\
\text { deficient }\end{array}$ & & Control (7) & $\begin{array}{c}\text { Magnesium (6) } \\
\text { deficient }\end{array}$ \\
\hline $\mathrm{Mg}, m E q / 5$ days & $1.91 \pm 0.22$ & $0.49 \pm 0.06^{*}$ & & $1.07 \pm 0.15$ & $0.10 \pm 0.03^{*}$ \\
$\mathrm{Ca}, m E q / 5$ days & $1.12 \pm 0.20$ & $1.00 \pm 0.15$ & & $0.56 \pm 0.10$ & $0.48 \pm 0.03$ \\
$\mathrm{P}, m g / 5$ days & $52.5 \pm 5.1$ & $90.9 \pm 8.7^{*}$ & & $26.5 \pm 3.9$ & $74.5 \pm 8.5^{*}$ \\
\hline
\end{tabular}

All values given as mean \pm SEM. Numbers in parentheses indicate the number of animals.

* Significantly different from controls at $P<0.001$. 
TABLE VII

Total Carcass Analysis after $4 \mathrm{Wk}$ of the Experimental Regimen

\begin{tabular}{|c|c|c|c|c|}
\hline & \multicolumn{2}{|c|}{ Intact rats } & \multicolumn{2}{|c|}{ Parathyroidectomized rats } \\
\hline & Control (12) & $\begin{array}{c}\text { Magnesium (10) } \\
\text { deficient }\end{array}$ & Control (0) & $\begin{array}{c}\text { Magnesium (7) } \\
\text { deficient }\end{array}$ \\
\hline & \multicolumn{4}{|c|}{ mmoles $/ 100 \mathrm{~g}$ fat-free dry solids } \\
\hline $\mathrm{Mg}$ & $7.8 \pm 0.15$ & $6.5 \pm 0.16^{*}$ & $8.7 \pm 0.23$ & $7.5 \pm 0.14^{*}$ \\
\hline $\mathrm{Ca}$ & $130.0 \pm 1.6$ & $140.0 \pm 1.4^{*}$ & $130.0 \pm 2.9$ & $140.0 \pm 3.3$ \\
\hline $\mathrm{P}$ & $95.0 \pm 1.8$ & $100.0 \pm 0.8^{*}$ & $97.0 \pm 3.0$ & $104.0 \pm 1.5 \ddagger$ \\
\hline $\mathrm{Na}$ & $19.5 \pm 0.21$ & $20.8+0.17^{*}$ & $21.3 \pm 0.37$ & $22.7 \pm 0.39 \ddagger$ \\
\hline $\mathrm{K}$ & $27.7 \pm 0.38$ & $26.5 \pm 0.26$ & $27.0 \pm 0.36$ & $26.1 \pm 0.36 \ddagger$ \\
\hline $\mathrm{Cl}$ & $10.8 \pm 0.16$ & $11.0 \pm 0.16$ & $10.0 \pm 0.14$ & $9.8 \pm 0.17$ \\
\hline $\begin{array}{l}\text { Total water, } g / 100 \mathrm{~g} \\
\text { fat-free dry solids }\end{array}$ & $248.0 \pm 0.9$ & $246.0 \pm 1.6$ & $249.0 \pm 0.8$ & $237.0 \pm 3.6 \ddagger$ \\
\hline
\end{tabular}

All values given as mean \pm SEM. Numbers in parentheses indicate the number of animals.

* Statistically significant at $P<0.01$.

¥ Statistically significant at $P<0.05$.

of the magnesium-deficient animals, whereas potassium content is diminished. The changes in chloride content are not significant.

\section{DISCUSSION}

The hypercalcemia observed in experimental magnesium deficiency has not been satisfactorily explained. Its common observation has stimulated speculation concerning the relationship between the metabolism and homeostasis of the two main divalent cations, calcium and magnesium. Thus, MacIntyre and Daviclson (1) have ascribed the hypercalcemia to an increased positive balance owing to a diminished urinary and fecal excretion of calcium. This, in turn, is suggested to be a consequence of a common transport mechanism for these ions by both the gut and renal tubular cells. Hence, when the available magnesium is limited, calcium competes more favorably for transport and more is absorbed by the gastrointestinal tract and the renal tubules (1). Richardson and Welt (23) on the other hand have demonstrated that a difference in the positive balance of calcium is not a necessary condition for the hypercalcemia of magnesium deficiency. Alternatively, an increase in the activity of the parathyroid gland has been suggested $(3,24)$.

The present study indicates that intact parathyroid glands are essential for the augmented concentration of calcium and depressed concentration of phosphorus in plasma in magnesium deficiency, since magnesium-deficient parathyroidectomized animals fail to develop these alterations when compared with their non-magnesium-deficient parathyroidectomized controls. More significantly, when the duration of magnesium deficiency is extended to $6 \mathrm{wk}$, the parathyroidectomized animais have a concentration of calcium in plasma that is, in fact, lower than that of their appropriate controls.

The partition of plasma calcium provicles a pathophysiologic explanation for these olservations. Magnesium-cleficient, parathyroiclectomized animals developed a significantly lower concentration of ionic calcium in plasma in comparison to their magnesium-replete, parathyroiclectomized controls. Although the specific mechanisms involved in this alteration were not delineated, the additional observation that the complexed calcium fraction was maintained in the presence of a lower concentration of ionic calcium suggests that one factor in this response was a shift of calcium in plasma to chelation sites formerly occupied by magnesium. In the animal with intact parathyroid glands, this decrease in ionic calcium would serve to stimulate the parathyroid gland and the concentration of ionic calcium would be restored to normal. However, this mechanism could not explain the significant increase in the concentration of ionic calcium which was demonstrated in magnesiumdeficient rats with intact parathyroid glands and which could be simulated by the exogenous admin- 
istration of parthyroid extract. Since the presence of intact parathyroid glands is essential for this response, it must be concluded that some consequence of magnesium deficiency is capable of modifying the regulatory processes within the parathyroid gland that are involved in maintaining a normal concentration of ionic calcium in plasma. This does not necessarily imply that there need be an enhanced secretion of parathormone in this circumstance; however, the probability that this may, in fact, occur can be inferred from the observed diminution in the concentration of ionic calcium in magnesium-deficient, parathyroidectomized animals.

The modification in parathyroid function demonstrated in this study might be related to the low concentration of magnesium in plasma, or to some other consequence of the total body magnesium deficit. One cannot discriminate between these two possibilities from these data alone. Gitelman, $\mathrm{Ku}$ kolj, and Welt (25) have presented data that must be interpreted to imply that parathormone activity is suppressed by hypermagnesemia. Moreover, hypermagnesemic perfusion of the parathyroid gland in cattle has been observed to diminish the secretion of parathormone (26). These observations are compatible with the possibility that the concentration of magnesium in plasma per se may influence the functional activity of the parathyroid gland and, in turn, suggest that the modification in parathyroid gland function clemonstrated in this study is related to the depressed plasma concentration of magnesium.

There have been several attempts to relate magnesium metabolism to parathyroid hormone activity, mainly because of the numerous similarities in the chemical and biological behavior of the two divalent cations, calcium and magnesium. There are some reports that the administration of high closes of parathyroid hormone produces in animals a decrease in urinary excretion $(4,5)$ and an increase in the plasma levels of magnesium $(3,6,7)$ and that parathyroidectomy produces an early decrease in plasma magnesium which later returns to normal values $(6,8-10)$. These changes, nevertheless, are not as reproducible, marked, or persistent as the effects upon calcium metabolism produced by the same measures. Thus, it is apparent that there may well be a relationship between the parathyroid gland and magnesium metabolism, but that this relationship is different, at least in intensity, from the direct way in which calcium and parathyroid hormone are related.

In magnesium-deficient rats marked hyperphosphaturia is a constant feature which appears soon after magnesium is restricted in the food (1$3,27)$. Although this is consistent with a state of hyperparathyroidism, its appearance cannot be entirely ascribed to increased parathyroid activity since it is present to a comparable degree in all the magnesium-deficient rats of this study and is not related to the presence or absence of the parathyroid gland $(3,27)$. Parathyroid overactivity may play a role in this hyperphosphaturia, but is obviously not an essential feature.

There is nephrocalcinosis in the kidneys of magnesium-deficient animals which is confined to the broad ascending limb of the loop of Henle $(2,28)$. There may well be other functional lesions unassociated with detectable structural alterations that may be responsible for the hyperphosphaturia. This possibility is strengthened by the fact that this increased excretion of phosphate occurs in the face of a presumed decrease in glomerular filtration rate (as deduced from increased levels of urea nitrogen) and hypophosphatemia. This combination implies a diminished filtered load of phosphate and hence an increased phosphaturia must be interpreted to mean a reduction in the tubular reabsorption of phosphate (or conceivably an increase in phosphate secretion) in magnesium-deficient rats which is independent of parathyroid gland activity.

\section{ACKNOWLEDGMENTS}

This investigation was supported by U. S. Public Health Service Training Grant No. T1-AM-5054 and Research Grant Nos. 5-R01-HE-01301 and AM-08685. Dr. Kukolj performed this work during the tenure of a Rockefeller Foundation Fellowship. Dr. Welt was supported by U. S. Public Health Service Research Career Award No. 5-K6-AM-934.

\section{REFERENCES}

1. MacIntyre, I., and D. Davidson. 1958. The production of secondary potassium depletion, sodium retention, nephrocalcinosis and hypercalcemia by magnesium deficiency. Biochem. J. 70: 456.

2. Whang, R., and L. G. Welt. 1963. Observations on experimental magnesium depletion. J. Clin. Invest. 42: 305 .

3. Heaton, F. W. 1965. The parathyroid glands and magnesium metabolism in the rat. Clin. Sci. 28: 543. 
4. MacIntyre, I., S. Boss, and V. A. Troughton. 1963. Parathyroid hormone and magnesium homeostasis. Nature. 198: 1058.

5. Soffer, L. J., C. Cohn, E. B. Grossman, M. Jacobs, and H. Sobotka. 1941. Magnesium partition studies on Graves' disease and in clinical and experimental hypothyroidism. J. Clin. Invest. 20: 429.

6. Durlach, J., M. Stoliaroff, J. Gauduchon, R. Leluc, and T. Cong-Trieu. 1960. Study on the relation between the parathyroids and magnesium metabolism. Ann. Endocrinol. 21: 235.

7. Greenberg, D. M., and M. A. Mackey. 1932. The effect of parathyroid extract on blood magnesium. J. Biol. Chem. 98: 765.

8. Roberts, B., J. J. Murphy, L. Miller, and O. Rosenthal. 1954. The effect of parathyroid hormone upon serum levels and urinary excretion of magnesium. Surg. Forum. 5: 509.

9. Payne, J. M., and J. Chamings. 1964. The effect of thyro-parathyroidectomy in the goat with particular respect to clinical effects and changes in the concentrations of plasma calcium, inorganic phosphorus and magnesium. J. Endocrinol. 29: 19.

10. Talmage, R. V. 1962. Action of parathyroids on bone studied with radioisotopes. In Radioisotopes and Bone; a symposium. F. C. MacLean, P. Lacroix, and A. M. Budy, editors. Blackwell Scientific Publications, Oxford. 149.

11. Harrison, H. E., D. C. Darrow, and H. Yannet. 1936. The total electrolyte content of animals and its probable relation to the distribution of body water. J. Biol. Chcm. 113: 515.

12. Hastings, A. B., and L. Eichelberger. 1937. The exchange of salt and water between muscle and blood. I. The effect of an increase in total body water produced by the intravenous injection of isotonic salt solutions. J. Biol. Chem. 117: 73.

13. Marsh, W. H., B. Fingerhut, and E. Kirsh: 1957. Determination of urea nitrogen with the diacetyl method and an automatic dialyzing apparatus. $A m . J$. Clin. Pathol. 28: 681.

14. Cotlove, E., H. V. Trantham, and R. L. Bowman. 1958. An instrument and method for automatic, rapid, accurate, and sensitive titration of chloride in biologic samples. J. Lab. Clin. Med. 51: 461.
15. Gitelman, H. J. 1967. An improved automated procedure for the determination of calcium in biologic specimens. Anal. Biochem. 18: 521.

16. Gitelman, H. J., C. Hurt, and L. Lutwak. 1966. An automated spectrophotometric method for magnesium analysis. Anal. Biochem. 14: 106.

17. Chen, P. S., Jr., T. Y. Toribara, and H. Warner. 1956. Microdetermination of phosphorus. Anal. Chem. 28: 1756.

18. Meites, S., and W. R. Faulkner. 1962. In Manual of Practical Micro and General Procedures in Clinical Chemistry. Charles C Thomas, Springfield, 94.

19. Lane, K., and P. S. Chen, Jr. 1960. Rapid determination of citric acid in biological fluids. Atomic Energy Commission Research and Development Report, UR 579, University of Rochester Atomic Energy Project.

20. Walser, M. 1961. Ion association. VI. Interactions between calcium, magnesium, inorganic phosphate, citrate and protein in normal human plasma. J. Clin. Invest. 40: 723.

21. Walser, M. 1960. Determination of free magnesium ions in body fluids. Improved methods for free calcium ions, total calcium, and total magnesium. Anal. Chem. 32: 711.

22. Walser, M. 1961. Ion association. V. Dissociation constants for complexes of citrate with sodium, potassium, calcium and magnesium ions. J. Phys. Chem. 65: 159.

23. Richardson, J. A., and L. G. Welt. 1963. The hypercalcemia of magnesium depletion. Clin. Res. 11: 68 . (Abstr.)

24. Alcock, N., and I. MacIntyre. 1964. Some effects of magnesium repletion on calcium metabolism in the rat. Clin. Sci. 26: 219.

25. Gitelman, H. J., S. Kukolj, and L. G. Welt. 1966. Inhibition of parathyroid gland function by hypermagnesemia. Federation Proc. 25: 495. (Abstr.)

26. Care, A. D., L. M. Sherwood, J. T. Potts, Jr., and G. D. Aurbach. 1966. Perfusion of the isolated parathyroid gland of the goat and sheep. Nature. 209: 55.

27. Ginn, H. E., and L. L. Shanbour. 1967. Phosphaturia in magnesium-deficient rats. Am. J. Physiol. 212: 1347.

28. Oliver, J., M. MacDowell, R. Whang, and L. G. Welt. 1966. The renal lesions of electrolyte imbalance. IV. The intranephronic calculosis of experimental magnesium depletion. J. Exptl. Med. 124: 263. 